\title{
Intracranial Hemorrhage In Preterm Newborn
}

\author{
Manal Sayed Ramadan, M.D*. Hanan Eissa, M.D. **
}

\begin{abstract}
Intracranial hemorrhage (ICH) in neonates is an acquired lesion with enormous potential impact on morbidity, mortality , and long-term neurodevelopmental outcome.this study was done to study the prevalence of $\mathrm{ICH}$ in preterm neonates without any neurological signs detected and to determine the different obstetric and neonatal risk factors associated with the development of ICH .Case - control study throughout the period from June 2011 to December 2011 .This study was conducted on 58 preterm neonates who were admitted to Neonatal Intensive Care Unit (NICU) of Obstetrics and Gynecology Hospital , Ain Shames University. Detailed history taking: maternal, obstetric and delivery circumstances laying stress on maternal and obstetric risk factors of ICH. Assessment of the general condition using APGAR score at 1and 5 minutes. Assessment of gestational age (GA) using Ballard score. Assessment of birth weight, thorough clinical examination laying stress on neurological examination according to Sarnat. Imaging studies using cranial ultrasound (CUS) on 3rd days of life. The prevalence of asymptomatic cases with ICH was $60.7 \%$. There are certain maternal and neonatal risk factors that are associated with increased risk of ICH. CUS can be considered as a specific and sensitive indicator for occurrence of ICH
\end{abstract}

\section{Introduction:}

Intracranial hemorrhage $(\mathrm{ICH})$ in neonates is an acquired lesion with enormous potential impact on morbidity, mortality, and long-term neuro-developmental outcome $\{1\}$.

Bleeding within the skull can occur external to the brain into the epidural, subdural or subarachnoid space, into the parenchyma of the cerebrum or cerebellum or, into the ventricles from the subependymal germinal matrix (GM) or choroids plexus $\{2\}$. Of all types of $\mathrm{ICH}$, germinal matrix-intraventricular hemorrhage (GM-IVH) is the most common and distinctive pathology $\{3\}$.

Periventricular-intraventricular hemorrhage (PIVH) is a major cause of neurological disabilities in preterm newborns $\{4\}$. Diagnosis typically depends on clinical suspicion, when an infant presents with typical neuralgic signs such as, seizures, irritability, or depressed level of consciousness and or with focal neuralgic deficits referable either to the cerebrum or brain stem $\{5\}$.

The associated clinical signs of IVH are typically nonspecific or absent, therefore it is recommended that premature infants $<34$ week GA should be evaluated with routine real time CUS through the anterior fontanel to screen for IVH within the first 3-5 days of age. CUS is the preferred imaging technique for screening because it is non-invasive, portable reproducible, sensitive and specific for detection of $\operatorname{IVH}\{6,7$, and 8$\}$ Aim of this study Studying the prevalence of $\mathrm{ICH}$ in preterm neonates without any neurological signs detected and Assessing the different obstetric and neonatal risk factors associated with the development of ICH Patients

This case- control study was conducted on 58 preterm who were admitted to Neonatal Intensive Care Unit (NICU) of Obstetrics and Gynecology Hospital, Ain Shams University throughout the period from June 2011

* Pediatric Department of Ahmed Maher Teaching hospital

**Radio Diagnosis department of Ain shams university Hospital to December 2011. An informant written consent was taken from parents of each patient.

The studied neonates were divided into two groups:

1-Cases with ICH group .2-Cases without ICH group.

Subdivision of cases with ICH into two subgroups:

1-Symptomatic group (with neurological signs).

2-Asymptomatic group (without neurological signs).

Inclusion criteria:-

Preterm neonates $<37$ week gestational age

Exclusion criteria:-

1- Extreme low birth weight newborns $(<1000$ grams of birth weight).

2- Congenital malformation of the brain

3- Neonatal sepsis such as meningitis, encephalitis

\section{Methods:}

All neonates were subjected to:

1-Detailed history taking: maternal , obstetric and delivery circumstance laying stress on maternal and obstetric risk factors of ICH assessment of the general condition using apgar score at $1 \quad \& \quad 5 \quad$ min $\{9\}$.Assessment of gestational age using Ballard score $\{10\}$. Anthropometric measurement (birth weight, head circumference)

2-Thorough clinical examination laying stress on neurological exam. According to Sarnat stages $\{11\}$. Assessment of the need of the ventilator support.

3-Investigations:- A-Laboratory:-Complete blood count (CBC), C-reactive protein, Arterial blood gases (ABG) B-Cranial ultrasound : on 3rd day of birth transcranial ultrasound was used via anterior fontanel using GE LOG IQ3 probe, using $8 \mathrm{MHz}$ probe, $8 \mathrm{C}$ ( convex ), 8L ( linear ).

PIVH was graded into 4 grades according to the papile grading $\{12\}$ :-

Grade I: Isolated GMH (no PIVH) 


\section{Manal Sayed Ramadan, et al}

Grade II: PIVH without Ventricular dilation

Grade III: PIVH with Ventricular dilation

Grade IV: PIVH with parenchymal hemorrhage

\section{Statical analysis:-}

The data were coded, entered and processed on computer using SPSS (version 15). The level $\mathrm{P}<0.05$ was considered the cut-off value for significance. Results this case - control study was conducted on 58 preterm were admitted to the NICU of Gynecology and obstetrics Hospital Ain Shams University Hospital during the study period from June 2009 to December 2009. 28 of them( $48.3 \%)$ were $\mathrm{ICH}$,in which 20 cases $(71.4 \%)$ male , 8 cases $(28.6 \%)$ female , 19 cases $(67.8 \%)$ delivered vaginally, 9 cases $(32.2 \%)$ cesarean section ,their mean gestational age was 30.4 weeks , and their mean birth weight was $1.3 \mathrm{Kg}$, their mean Apgar score at 1 minutes was 0.79 and at 5 minutes was 3.27. 30 were cases without ICH in which 12 of them ( $40 \%$ ) male, 18 of them $(60 \%)$ female, 17 of them $(56.6 \%)$ delivered vaginally , $13(43.4 \%)$ cesarean section their mean gestational age was 33.4 weeks ,and their mean birth weight was $2.6 \mathrm{Kg}$, their mean Apgar score at 1 minutes was 5.6 and at 5 minutes was 8.5 (figure 1 and 2). Percentage of cases with ICH was $48.3 \%$ (28cases). Grade one IVH was the commonest representing $53.5 \%$ (15 cases), grade II was $17.9 \%$ (5 cases), grade III $17.9 \%$ (5 cases), grade IV $10.7 \%$ (3cases) There are certain maternal factors that are associated with increased risk of $\mathrm{ICH}$, including, prolonged and instrumental delivery by forceps and ventose extraction were the commonest representing $25 \%, 21.4 \%$ was PROM, $17.8 \%$ was male presentation (table 1) There are certain neonatal factors that are associated with increased risk of $\mathrm{ICH}$, including , prematurity , pneumothorax , trauma , mal-presentation , ventilator use, Increase $\mathrm{CO} 2$ (table 2) Mortality rate was $35.7 \%$ ( 10 cases) in cases with ICH in comparison to cases without ICH was $16.6 \%$ (5 cases). The sensitivity of CUS for detection of ICH was $92.8 \%$, the specificity of CUS was higher representing $96.6 \%$ and positive predictive value of CUS for detection of ICH was $96.2 \%$ (figure 5) In the current study it was found that the neurological signs were detected in $39.3 \%$ of cases with ICH while $60.7 \%$ were asymptomatic (table 3 ).

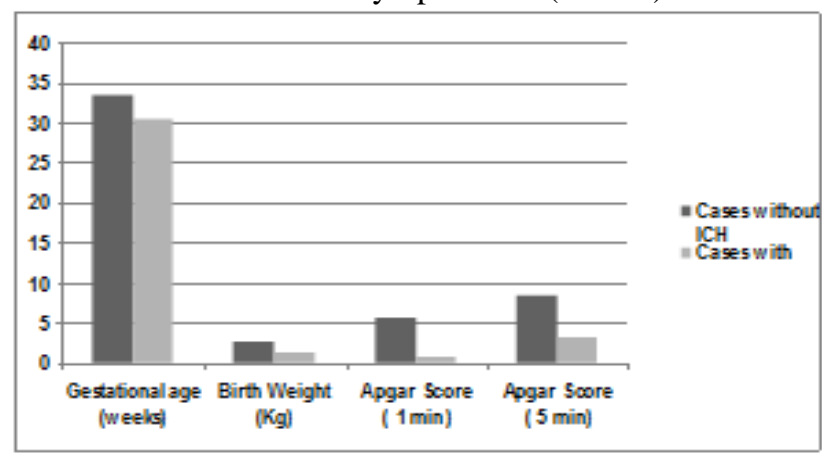

Figure(1) GA,birth weight,Apgar score

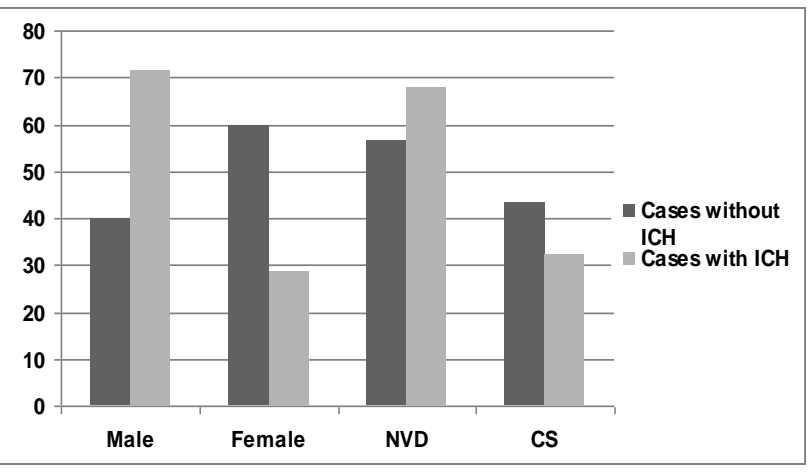

Figure(2)Sex,MOD

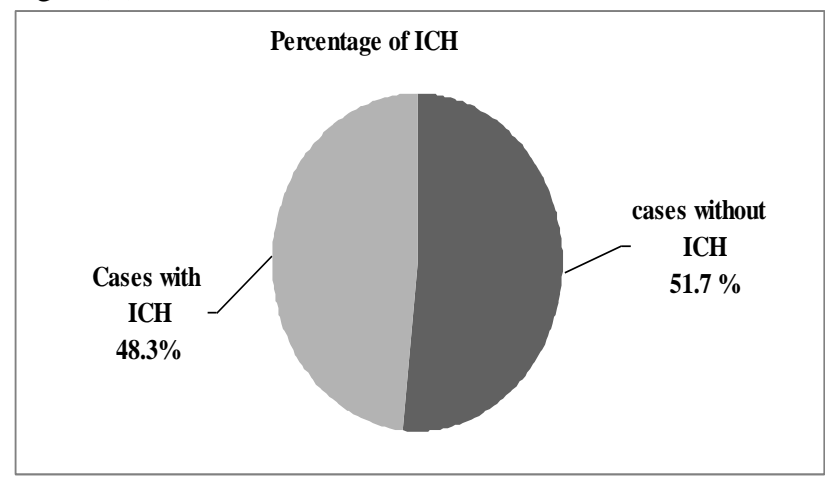

Figure(3) Percentage of cases with ICH

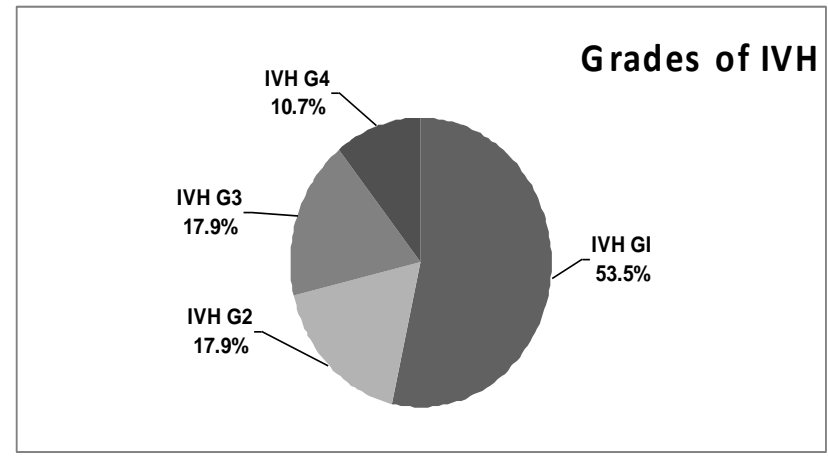

Figure (4)Grades of IVH

This case-control study was conducted on 58 preterm, 28 of them $(48.3 \%)$ were IVH. Grad one IVH was the commonest representing $53.5 \%$, grade II was $17.9 \%$, grade III $17.9 \%$, and grade IV $10.7 \%$ this was in agreement with Kadri $\{13\}$ who was found that the incidence of PIVH among preterm neonates was $44.68 \%$. The majorities were mostly grade I Lee $\{4\}$ was found that $79.7 \%$ with grad I IVH, $6.9 \%$ grad II As regard the GA we found that there was highly significant lower GA in which 22 preterm $<32 \mathrm{w}$ had ICH $(78.5 \%)$, this was in agreement with Dolfin $\{14\}$ who was found that the incidence of PIVH was $45 \%$ in infants $\leq 29$, weeks whereas in infants $>29$-weeksGA was $19 \%$. Lim $\{15\}$ was found that the massive IVH took place at $32 \mathrm{GA}$ Male gender showed significantly higher rate $(71.4 \%)$ of ICH than female $(28.6 \%)$, 


\begin{tabular}{|l|c|c|}
\hline Maternal risk factors & no & $\%$ \\
\hline Prolonged and vacuum - forceps delivery & 7 & $\mathbf{2 5}$ \\
\hline PROM & $\mathbf{6}$ & $\mathbf{2 1 . 4}$ \\
\hline Mal presentation & $\mathbf{5}$ & $\mathbf{1 7 . 8}$ \\
\hline Multiple pregnancy & $\mathbf{3}$ & $\mathbf{1 0 . 7}$ \\
\hline Toxemia of pregnancy & 3 & $\mathbf{1 0 . 7}$ \\
\hline Diabetic vasculopathy & 1 & $\mathbf{3 . 5}$ \\
\hline Pulmonary disease & 1 & 3.5 \\
\hline Polyhydramnions & 1 & 3.5 \\
\hline Placental abnormality & 1 & 3.5 \\
\hline
\end{tabular}

Table (1) Maternal risk factors among mothers of cases with ICH, PROM = premature rupture of membrane.

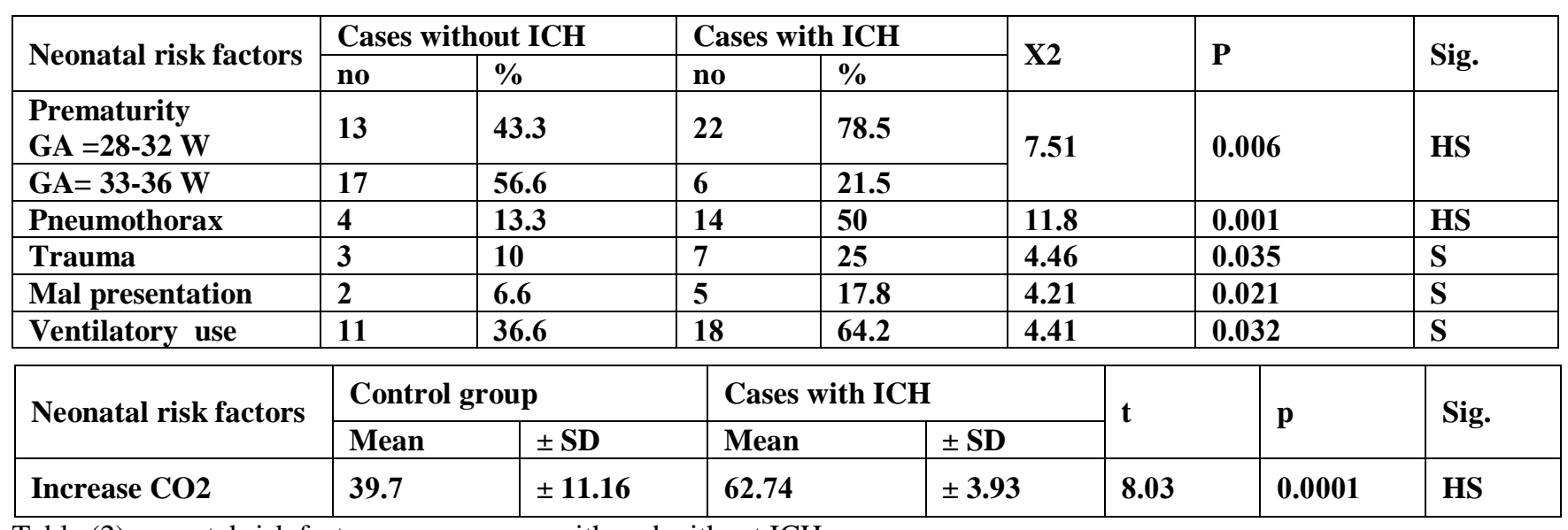

Table (2) neonatal risk factors among cases with and without ICH

\begin{tabular}{|c|c|c|c|c|c|c|c|}
\hline \multirow{3}{*}{$\begin{array}{l}\mathrm{CO} 2=\text { Carbon dioxide } \\
\text { Neurological signs }\end{array}$} & \multirow{2}{*}{\multicolumn{2}{|c|}{$\begin{array}{l}\mathrm{X} 2=\text { Chi-square test } \\
\text { Cases without ICH }\end{array}$}} & \multirow{2}{*}{\multicolumn{2}{|c|}{$\begin{array}{l}\mathrm{t}=\text { Student } \mathrm{t} \text { test } \\
\text { Cases with ICH }\end{array}$}} & obabili & \multirow{3}{*}{$\mathbf{P}$} & \multirow{3}{*}{ Sig } \\
\hline & & & & & \multirow{2}{*}{$\mathrm{X} 2$} & & \\
\hline & no & $\%$ & no & $\%$ & & & \\
\hline Negative & 25 & 83.3 & 17 & 60.7 & \multirow[b]{2}{*}{3.71} & \multirow[b]{2}{*}{0.041} & \multirow[b]{2}{*}{$\mathbf{S}$} \\
\hline Positive & 5 & 16.7 & 11 & 39.3 & & & \\
\hline
\end{tabular}

Table (3): Neurological signs among cases with and without ICH

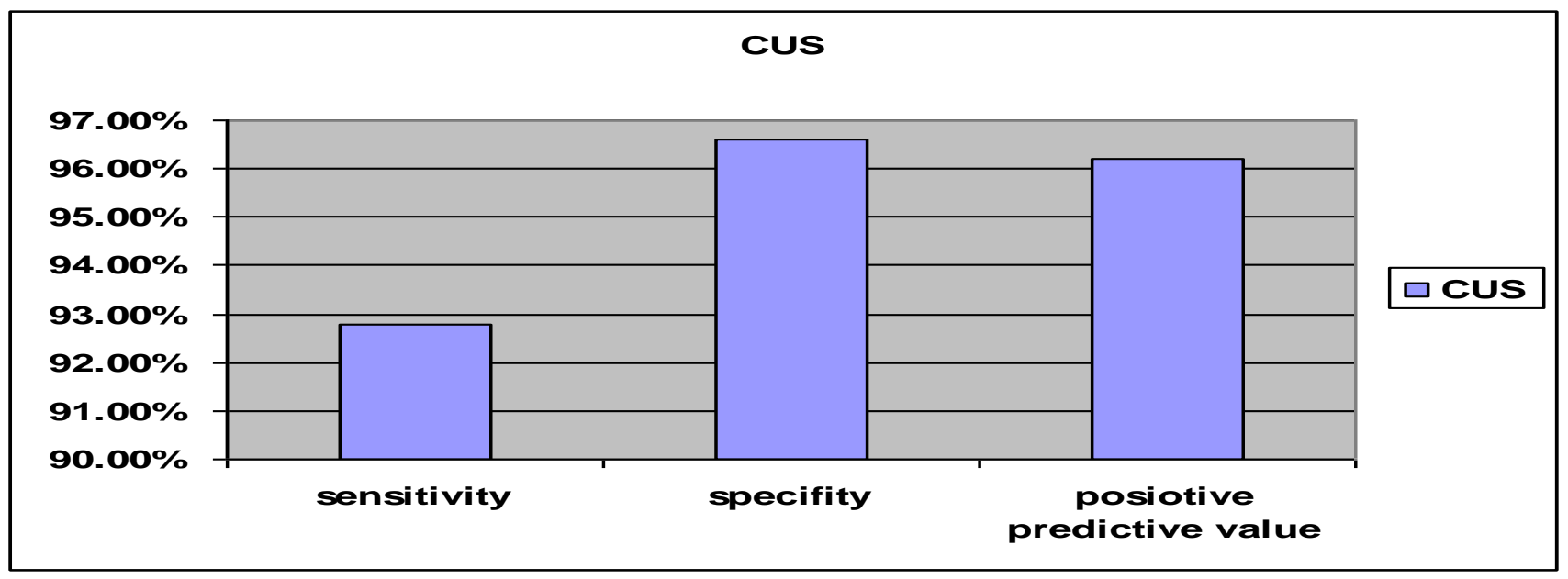

Figure (5): Sensitivity, specificity and positive predictive value of CUS for detection of ICH 


\section{Manal Sayed Ramadan, et al}
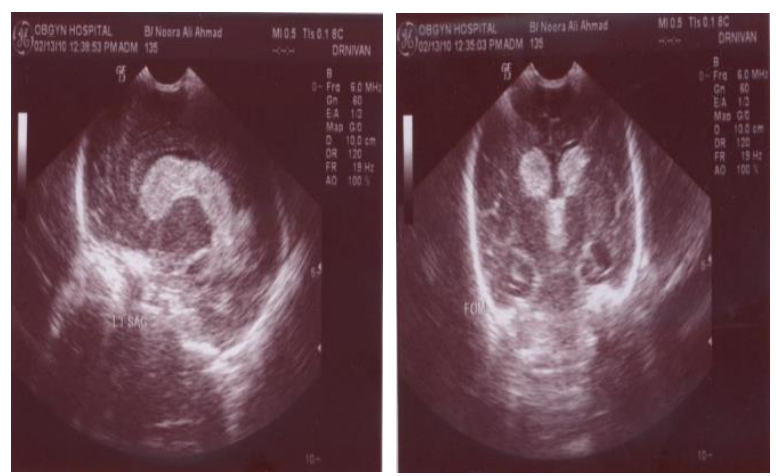

\section{Figure(6) CUS showing grade I}

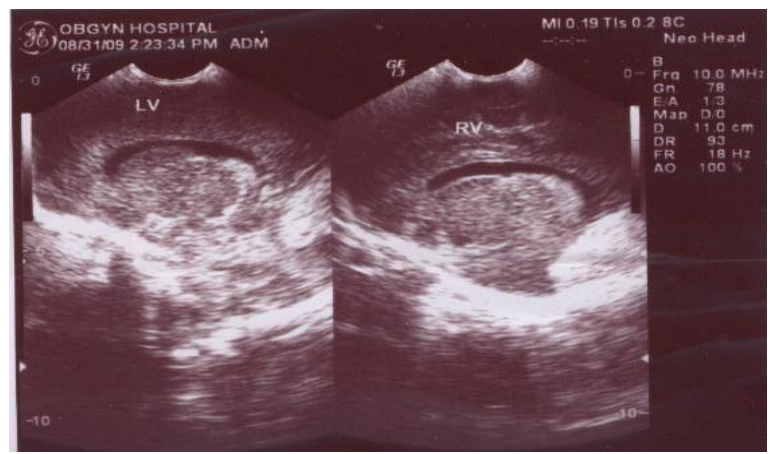

Figure(7) CUS showing grade II, IV,

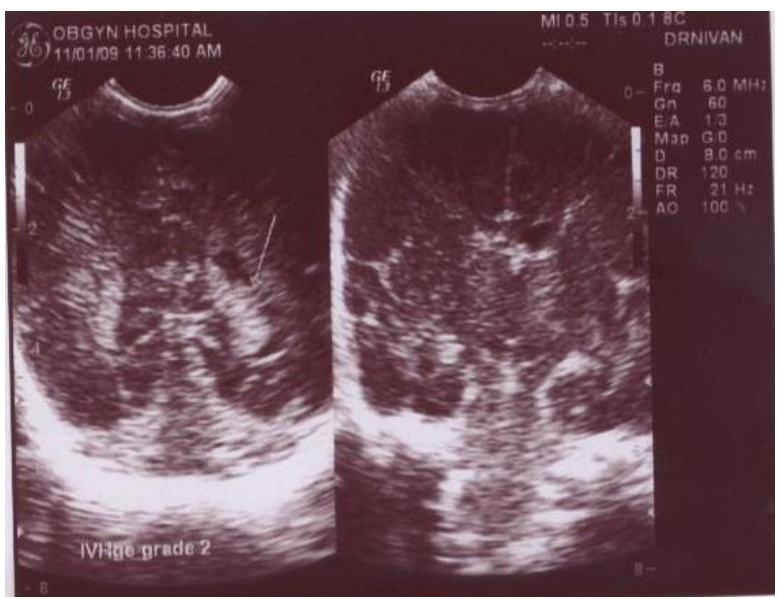

Figure (8) CUS showing grade III IVH

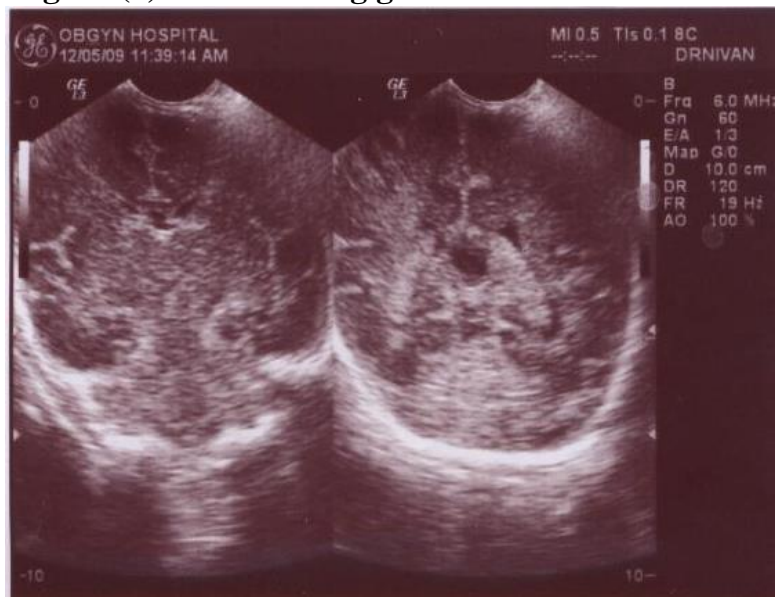

Figure (9) CUS showing grade IV IVH,

\section{Discussion}

this was in agreement with Tioseco $\{16\} \&$ Mohamed $\{17\}$ they were found that IVH significantly higher in male infants In this study it was found that there was a significant lower birth weight among cases with ICH $($ mean $=1.3 \mathrm{~kg})$ in comparison to cases without ICH $($ mean $=2.6 \mathrm{~kg})$. This finding was in agreement with the study done by Dykes $\{18\}$ who was found that, birth weight less than or equal to $1,200 \mathrm{gm}$, were associated with PIVH. Mohamed $\{17\}$ reported that the increased rates of IVH in boys were significant in the birth weight subgroups of < 1000 grams and 1000-1499 grams It was found that Apgar score was a highly significant lower at one minute and 5 minutes among cases with $\mathrm{ICH}$, This finding was in agreement with Baumert $\{19\}$ who was reported that lower Apgar score at 5 minutes was associated with greater risk of high IVH occurrence. It was found that among cases delivered vaginally, $67.8 \%$ developed ICH while only $32.2 \%$ of cases delivered by $\mathrm{CS}$ had ICH. This finding was in agreement with Towner $\{20\}$ who found that vaginal delivery with forceps assistance, ventose extraction were associated with an increased risk for ICH There are certain maternal factors that are associated with increased risk of $\mathrm{ICH}$, including, prolonged and instrumental delivery were the commonest representing $25 \%, 21.4 \%$ was PROM, $17.8 \%$ was male presentation, loony $\{21\}$ was reported that assisted vaginal delivery, maternal parity, fetal weight, PROM and prolonged duration of labor increase the risk of ICH newborns . There are certain neonatal factors that are associated with increased risk of ICH, including, pneumothorax, prematurity, trauma, nonvertex presentation, ventlatory use, increased $\mathrm{CO} 2$. These findings were in agreement with Khodapanahandeh $\{22\}$ reported that the following factors were associated with greater risk of high-grade IVH occurrence :lower GA, lower birth weight, mechanical ventilation, HMD , symptomatic hypotention, hypercapnia and lower Apgar score at 5 minutes. In the current study it was found that the neurological signs were detected in $39.3 \%$ of cases with ICH while $60.7 \%$ were asymptomatic. This finding were in agreement with loony $\{21\}$ who found that there was high prevalence of ICH in asymptomatic newborns, ICH causes more subtle injury to the developing brain The sensitivity of CUS for detection of ICH was $92.8 \%$ ,the specificity of CUS was higher representing $96.6 \%$ and positive predictive value of CUS for detection of ICH was $96.2 \%$,this finding were in agreement with Khan $\{7\}$ who stated that CUS examination provides a relatively sensitive and highly specific means of detecting IVH . In the present study it was found that the mortality rate among cases with $\mathrm{ICH}$ was $35.7 \%$, in comparison to cases without ICH was $16.6 \%$, Gomella $\{23\}$ was reported that the mortality rate in cases with mild to moderate PIVH was 5-10\%,20\% with sever PIVH,50\% with severe PIVH and parenchymal involvement. 
Conclusion:

The prevalence of asymptomatic cases with $\mathrm{ICH}$ was $60.7 \%$. There are certain maternal and neonatal risk factor that are associated with increased risk of ICH. CUS can be considered as a specific and sensitive indicator for occurrence of $\mathrm{ICH}$ recommendation Good perinatal care, avoid instrumental delivery. Routine screening using CUS are recommended for all infants born at 34 weeks' gestation or earlier and for all VLBW infants $(<1500$ grams of birth weight).

\section{References:}

1-Bassan H (2009): Intracranial hemorrhage in the preterm infant: understanding it, preventing it. Clin Perinatol; 36 (4): 737 - 62.

2-Volpe JJ (2001): Intracranial hemorrhage: subdural, primary subarachnoid, intracerebral, intraventricular (term infant), and miscellaneous. Neurology of the newborn . Philadelphia: WB Saunders; 397- 427.

3-Volpe JJ (2008): Intracranial hemorrhage: neurology of the newborn. 5th edition. Philadelphia: W.B Saunders Co; p. 481 - 588.

4-Lee JY, Kim HS, Jung E, Kim ES, Shim GH, Lee HJ, Lee JA, Choi CW , Kim EK, Kim BI, Choi JH (2010): Risk factors for periventricular - Intraventricular Hemorrhage in premature infants . J Korean Med Sci; 25(3): 418-24

5-Soul JS (2008): Intracranial Hemorrhage and Periventricular Leukomalacia. Manual of Neonatal Care. Sixth edition; 27(B): 499 - 518.

6-Kliegman, Behrman, Jenson, Stanton (2008): Intracranial - Intraventricular Hemorrhage and periventricular leukomalacia. Nelson textbook of pediatrics, 18th edition, Philadelphia, PA 191032899, Saunders Elsevier ;99(3):715-717.

7-Khan IA, Wahab S, Khan RA, Ullah E, Ali M (2010): Neonatal Intracranial Ischemia and Hemorrhage : Role of Cranial Sonography and CT Scanning . J Korean Neurosurg Soc; 47 (2): $89-94$

8-Miranda P (2010): Intraventricular hemorrhage and post hemorrhagic hydrocephalus in preterm infant. Minerva Pediatric; 62 (1): 79-89.

9-Apgar VA (1953): proposal for a new method of evaluation of the new born infant Analgesia. 32:260 10-Ballard JI, khoury J C, Wedig K,Wang L, Eilers Walsman and Lipo R( 1991): New Ballard score, expanded to include extremely premature infants . J Pediatric , 119 (3):417-423.
11-Sarnat H.B. and sarnat M.S. (1976): Neonatal encephalopathy following fetal distress. Archives of Neurology, 33: 696 -705.

12-Papile LA, Burstein J, Burstein R, (1978) et al .Incidence and evolution of subependymal and intraventricular hemorrhage: A study of infants with birth weights less than $1.500 \mathrm{gm} J$ pediatr; 92; 529534.

13-Kadri H, Mawla AA, Kazah J et al (2006): The incidence, timing, and predisposing factors of germinal matrix and intraventricular hemorrhage (GMH/IVH) in preterm neonates.Child Nerv Syst; 22(9):1086-90.

14-Dolfin T, Skidmore MB, Fong KW, Hoskins EM, Milligan JE, Moore DC, Shennan AT(1994):Perinatal factors that influence the incidence subependymal and intraventricular hemorrhage in low birthweight infants.AM J Perinatol;1(2):107- 13.

15-Lim LW, Volkodav OV (2009): Germinal matrx hemorrhage of prematurity: treatment approaches and outcomes in a single institutional review in the Ukraine. Pediatr Neurosurg; 45 (2): 132 - 40.

16-Tioseco JA, Aly H, Essers J, Patel K, El-Mohandes AA (2006) : Male sex and intraventricular hemorrhage . Pediatr Crit Care Med; 7(1): 40-4.

17-Mohamed MA, Aly H (2010): Male gender is associated with intraventricular hemorrhage. Pediatrics; 125 (2): e333 - 9.

18-Dykes FD, Lazzara A, Ahmann P, Blumenstein B, Schwartz J, Brann AW(2000): Intraventricular hemorrhage: a prospective evaluation of etiopathogenesis. Pediatrics; 66(1):42-9.

19-Baumert M, Broze KG , Paprotny M, Walencka Z, Sodowska H, Cnota W, Sodowski K ( 2008 ) : Epidemiology of peri / intraventricular hemorrhage in newborns at term . J physiology pharmacology; 59 supple 4: 67-75.

20-Towner D, Castro MA, Eby - Wilkens E, Gilbert WM (1999): Effect of mode of delivery in nulliparous women on neonatal intracranial injury. N Engl J Med; 341 (23): 1709- 1714.

21-Looney CB, smith JK, Merck LH, Wolfe HM, Chescheir NC, Hamer RM and Gilmore JH(2007): Intracranial hemorrhage in asymptomatic neonates : prevalence on MR images and relationship to obstetric and neonatal risk factors . Radiology; 242 (2):535-41 